\title{
DE NUEVO SOBRE LA OBRA ANTIISLÁMICA ATRIBUIDA A RAMÓN MARTÍ, DOMINICO CATALÁN DEL SIGLO XIII
}

Por

JOSEP HERNANDO

EI P. Angel Cortabarría en un artículo, publicado en MIDEO, acerca de las fuentes árabes de la Explanatio Simboli de Ramón Martí, dominico catalán del siglo XIII, escribe: «Parmi les travaux de R. Martin, certains, dont l'attribution au dominicain catalan a été contestée, abordent des thèmes apologétiques en rapport avec l'Islam et je les signale ici pour qu'on puisse mieux comprendre l'attitude spirituelle et intellectuelle de l'auteur de l'Explanatio Simboli. Dans un de ces travaux, le De iudicandis veris et falsis prophetis... Un autre de ces travaux, la Quadruplex reprobatio, quaque éditée en 1550 sous le nom de Jean Gallus, est certainement d'origine spagnole et reflète de toute façon le milieu qui a été celui de R. Martin... Citons encore, dans le même genre, la Summa contra Coran, la Summa contra sarracenos et le De origine et progressu et fine Machometi” (1). De lo escrito por el P. Cortabarria cabe deducir que las obras antiislámicas atribuibles a Ramón Martí serían cuatro: Quadruplex reprobatio, Summa contra Coran, Summa contra Sarracenos y De origine et progressu et fine Machometi.

Por mi parte, en la «Dix-huitième Session d'Histoire du Midi» que tuvo lugar en Fanjeaux en 1982, en la que, por cierto, estuvo presente el P. Cortabarria, mi intervención versó sobre la obra antiislámica de Ramón Martí, llegando a la conclusión de que no hay diversas obras antiislámicas de Ramón Martí y sí títulos diversos con un contenido idéntico, cuya autoría no había por qué poner en duda (2). El año siguiente, por otra parte, publiqué el texto de uno de los tres manuscritos existentes de dicha obra: el del códice 46 de la Biblioteca Capitular de la Catedral de El Burgo

(1) A. CORTABARRIA BEITIA, O.P.: Les sources arabes de /'Explanatio Simbolis du dominicain catalan Raymond Martin, en MIDEO, 16 (1983), pág. 108.

(2) J. HERNANDO I DELGADO: Le «De Seta Machometi” du Cod. 46 d'Osma, oeuvre de Raymon Martin (Ramón Marti), en /slam et chrétiens du Midi (XIlle-XIVe s.), Cahiers de Fanjeaux 18, Toulouse, 1983, págs. 351-371. 
de Osma (Soria) (3).

D. Timoteo Rojo Orcajo en su Catálogo descriptivo de los códices que se conservan en la Santa Iglesia Catedral de El Burgo de Osma, al describir el códice n. ${ }^{\circ}$ 46, escribe: «6. Al folio 45r. De secta Mahometana. Ad ostendedum quod Mahometus... Folio 60v ... de similibus idem est judicium. [Un tratadito apologético contra la secta mahometana]» (4). En realidad el tratado lleva el título De Seta Machometi. Se trata, como veremos, del famoso tratado antiislámico conocido como Quadruplex reprobatio o también De origine, progressu et fine Machometi et de quadruplici reprobatione prophetiae eius. Por otra parte, el contenido de De Seta Mahometi del ms. 46 de la Biblioteca Capitular de la Catedral de El Burgo de Osma es el mismo que el del ms. 28B., s. XIV, ff. 200v-222r de los Archivos Generalicios O.P. en Roma y también que el del ms. Dd. I, s. XIV, pp. 451-458 de la Universidad de Cambridge, cuyo título o rúbrica es Tractatus contra Machometum.

Dada la persistencia de la historiografía en seguir considerando tales títulos como obras diversas atribuibles a Ramón Martí (5), añadiendo además otros títulos y, por consiguiente, otras obras, con el añadido de la duda sobre su autoría, partiendo del contenido de De Seta Machometi del ms. 46 de El Burgo de Osma (6), vamos a plantearnos dos problemas: el primero, sobre la identidad de contenido de los diversos tratados en relación con los diversos títulos que nos ofrecen los diversos manuscritos, las ediciones y la historiografía; el segundo, sobre su autoría.

El origen de tal persistencia se debe, en especial, a Laureano Robles, quien en Escritores dominicos de la Corona de Aragón (s. XIII-XV) (7), una vez reseñadas diversas obras de Ramón Martí, en concreto de Explanatio Simboli Apostolorum, Capistrum ludaeorum, Pugio Fidei, Vocabulista in Arabico, De erroribus philosophorum, escribe en 1971: «6. Suma contra el Corán (cf. Diago: Historia, fol. 137). No tenemos indicios de su autenticidad o existencia". Pero tres años más tarde, en Escritores Dominicos de la provincia de Aragón (8), rectifica y, demostrando una mejor información, atribuye a Ramón Martí cuatro tratados antiislámicos: «6. Suma contra el Corán (cf. Diago: Historia, fol. 137). No tenemos indicios de su autenticidad o existencia. 7. Quadruplex reprobatio (dudosa). Esta obra editada en 1550 bajo el nombre de Jean Gallus es considerada por M.-Th. d'Alverny de origen español. Tal vez pueda atribuirse a nuestro autor... 8. Contra Sarracenos (dudosa). Luis de Valladolid en su Tabula Alberti da este título. No podemos saber si se trata de una obra concreta o

(3) JOSEP HERNANDO: Ramón Marti (s. XIII). «De Seta Machometis o «De origine, progressu et fine Machomet et quadruplici reprobatione prophetiae eius», en «Acta Historica et Archaeologica Mediaevalia», 4 (1983), págs. 9.63.

(4) Publicado en «Boletín de la Real Academia de Historia», 94 (1929), págs. 655-792 y 95 (1929), págs. $152-314$ El fragmento citado se halla en las págs. $765-766$ del v. 94.

(5) «L'obra de Ramón Martí és netament apologètica... Hi pertanyen l'esmentada Explanatio symboli apostolorum, acabada en 1257, i unes Summes contra l'Alcorà, avui perdudes, però que Diago atribueix a Marti”, escribía E. VILANOVA en História de la teologida cristiana, vol. 1 Des dels orígens al segie XV. Ed. Herder, Barcelona, 1985, pág. 650. Tal afirmación se repite en la edición castellana aparecida en 1989.

(6) En adelante, cuando nos refiramos ai tratado antiislámico que contienen los manuscritos de El Burgo de Osma, Roma y Cambridge, lo haremos con el título o rúbrica De Seta Machometi, que es la del tratado de El Burgo de Osma.

(7) Publicado en Repertorio de Historia de las Ciencias Eclesiásticas en España, 3. Siglos XIII-XVI, Salamanca, 1971, págs. 58-67.

(8) Publicado en Escritores dominicos de la provincia de Aragón, Salamanca, 1974, págs. 76-77. 
de un título génerico. 9. De origine et progressu et fine Machometi (dudosa). Ricoldo en su Tractatus dice que copia de Ramón Martí. Según Secret se trata de un tratado editado dos veces en el siglo XVI bajo el nombre de Juan Gallus... 11. (Iohannes Gallensis: potius Raymundus Martini): Tractatus contra Machometum...». Laureano Robles finaliza su trabajo citando los tres manuscritos que contienen dicho Tractatus contra Machometum: el de los Archivos Generalicios O.P. en Roma, el de la Universidad de Cambridge y el de la Catedral de El Burgo de Osma, cuyo título es, como ya se ha dicho, De Seta Machometi.

En primer lugar, creo que será de interés tener presente el contenido del De Seta Machometi, según el ms. de El Burgo de Osma, o del Tractatus contra Machometum, según los ms. de Roma y Cambridge. Ello nos ayudará a clarificar algunas confusiones que se observan en el artículo citado de Laureano Robles y en los posteriores de otros autores que siguen basándose en éste. Para ello, dadas las limitaciones del presente artículo, estructuraremos el tratado utilizando las mismas frases del autor:

1. Signa seu fructus veri prophete vel nuntii Dei (9)

1.1. Quod sit verax

1.2. Quod sit bonus et virtuosus

1.3. Quod faciat miracula

1.4. Quod veniat ex lege bona et sancta. Talis fuit lex mosaica et evangelica

2. Usque ad predictos quadraginta annos fuerat in peccato scilicet ydolatrie (10)

2.1. Secudum quod legitur in libro qui vocatur Ciar, scilicet Actus Machometi (11)

2.2. Secudum quod legitur in diversis historiis que tanguntur in Alcorano et in aliis libris

2.3. Item, dicitur in libro qui vocatur Bochari (12)

2.4. Quod probatur in Alcorano

3. De falsa inspiratione Machometi (13)

(9) El principio del que parte ef autor es común en la critica religiosa para los teólogos cristianos de Oriente y Occidente: hay que rechazar la pretendida misión divina de Mahoma y, por consiguiente, el Islam, dado que no responde al modelo de la religión cristiana según es expuesta en la teología tradicional. De ahi que, lógicamente, sea la Biblia el principio de su crítica. Ahora bien, si Pedro el Venerable en Contra Sectam Saracenorum se pregunta quid prophetia sit, y lo mismo se hace en la Apologia de al-Kindi, el autor del tratado, Ramón Marti en realidad, se centra, de forma exclusiva, en la persona misma de Mahoma, es decir, parafraseando a Pedro el Venerable de qui res ignorat aut preteriti temporis aut presentis vel futuri, en el caso del día del juicio y el del desconocimiento de la trampa tendida por sus adversarios, lo presenta en el sentido de ataque personal: mentiroso y consecuencias indignas de un enviado de Dios. Cf. PEDRO EL VENERABLE: Contra Sectam Saracenorum, 11, 4, PL 187, col. 700; J. MUÑOZ SENDINO: La Apologia de al-Kind, en «Miscellanea Comillensis», 11-12 (1949), págs. 400 y ss.

(10) RAMÓN MARTÍ, como los polemistas cristianos orientales utiliza la parte biográfica de Mahoma anterior a su pretendida revelación con intención polémica, siguiendo fielmente la Sira de inb ishaq. Su finalidad es compararlo con el ideal moral: Jesús. El origen de Mahoma y su primera religión es la idoiatría. Por otra parte, la simple exposición de la vida de Mahoma, hasta su pretendida inspiración, es suficiente, sin necesidad de comentario, para mostrar su diferencia con Jesús: horfandad, falta de recursos, relaciones con la viuda jadiya.

(11) Sira o Sirat rasul Allah (vida del Profeta), redacta por el historiador Abü (Abd Allah Muhammad ibn Ishaq (en 767 o en 768). Perdido su original ha sobrevivido en la conocida recensión de Ibn Hišan (834). Ramón Marti, en lugar de la forma singular sira para designar una biografia en generai, utiliza la forma plural al-siyar, usada preferentemente en conexión con la biografia del Profeła. Cf. art. Sira, en A.R. GIBB; J.H. KRAMERS: Shorter Encyclopaedia of /slam, Leiden-London, 1961, pág. 547.

(12) RAMÓN MARTí toma al autor por su obra. Se trata de Șahin de al-Bujāri, el corpus de hadit de autoridad más indiscutida junto con el corpus compuesto por Muslim. Ramón Martí sólo cita estas dos compilaciones. De los 32 hadit citados, 24 pertenecen a la compilación de al-Bujart.

(13) El autor, igual que hiciera exponiendo sus origenes, se limita, por lo que hace a la pretendida inspiración de Mahoma, a citar, sin más, las diversas fuentes árabes admitidas sin discusión entre los musulmanes. Implícitamente subyace la pregunta: ¿qué testigo digno de fe habia alli? 
3.1. Ex verbis Axe, uxoris sue, possitis in libro qui vocatur Moslim (14)

3.2. Item, dicitur in libro qui vocatur Bochari secudum quod refert eadem Axa

4. De seta Sarracenorum (15)

4.1. Proximi eius

4.2. Quod interficerent seu expugnarent homines quousque testificarentur

4.3. Alii fatua simplicitate

4.4. Alii quia invenerunt parentes suos hoc errore deceptos

5. [De quadruplici reprobatione Machometi] (16)

5.1. Machometus fuit mendax (17)

5.1.1. Verba eius vera

5.1.1.1. Deus noster est ille qui creavit celum et terram

5.1.1.2. Deus preelegit et sanctificavit Mariam super mulieres

5.1.1.3. In Evangelio Christi est lumen et directio

5.1.1.4. Apostoli erant adiutores Dei

5.1.2. Verba eius falsa

5.1.2.1. Maria fuit filia Abrahe et soror Aaron (18)

5.1.2.2. Qui sequntur nuntium (Machometum) inveniunt eum scriptum in lege Moysi et in Evangelio

5.1.2.3. Christus prophetavit de se

5.1.2.4. (ludei) non interfecerunt (Christum), neque crucifixerunt eum, sed assimilatum

5.1.2.5. (Christiani in errore sunt)

5.1.2.6. Deus ponit homines in errore ut necessario fornicentur

5.1.2.7. In alia vita erunt fontes, fructus, uxores, tapecia de serico et puelle vel virgines (19)

(14) RAMÓN MARTÍ toma al autor por su obra, como hiciera con la compilación de al-Bujärt.

(15) Si la persona de Mahoma y su religión merecen el rechazo más absoluto, el autor no podía pasar por alto su éxito. Este éxito, propuesto por los polemistas islámicos como prueba de la verdad de su misión, por ejemplo, 'Alt ibn Sahl ibn Rabban al-Tabari en Kitab al-din Waldawla, ofrece diferencias notables con el éxito del Cristianismo. La fuerza, la estupidez, la ignorancia y el afán de riquezas son las razones del éxito del islam, como también constata la Antologia de al Kindi. Cf. C: ANAWATI: Polémique, Apologie et Dialogue IslamoChrétiens. Positions classiques, médiévales et positions contemporaines, en «Euntes Docete», 22 (1969), págs. 392-395; J. MUÑOZ SENDINO: La apología, cit., págs. 401, 419 y 425.

(16) Esta parte constituye el núcleo central de la obra polémica de Ramón Martí, por el que es conocida, es decir, la Quadruolex reprobatio: Mahoma fue mentiroso, no fue puro, no hizo milagros, sus leves son inmundas. Cabe destacar las diferencias de lenguaje entre nuestro autor y los polemistas antiislámicos orientales por lo que hace a los «calificativos» aplicados a Mahoma. Cf. A.TH. KHOURY: Polémique Byzantine contre /'Islam (VIle-XIl/e s.), Leiden, 1972

(17) Contra la pretendida autenticidad de la misión profética de Mahoma, el autor le presenta como ignorante, inculto, falsificador incluso de la verdad, necio y bufón. Confunde las personas de la Biblia: Maria, madre de Jesús, con María, la hermana de Moisés. Niega un hecho probado: la pasión y muerte de Jesús. Pretende que Jesús predijo su venida. Contra toda lógica, atribuye a Dios la causa del pecado. Pretende un paraíso réplica de la vida terrestre, que no se corresponde con la verdad contenida en la Biblia. Uno de los signos del verdadero profeta es la predicción del porvenir. Lo que predijo no se cumplió, por consiguiente mintió. Mahoma, pues, carece de credibilidad en su pretensión de profeta

(18) Se refiere lógicamente no a Abraham sino a '/mrän según el Corán y a Amram, padre de Moisés y Aarón, según Ex. 6, 20 y Nu. 26, 59, lo que parece atestiguar que Mahoma habia confundido a María, hermana de Moisés, con Maria, madre de Jesús. Ramón Martí polemiza teniendo en cuenta que el padre de María fue Joaquín.

(19) Dado el carácter polémico del tratado contra la pretendida misión profética de Mahoma, el autor, con ayuda de las auctoritates que le proporcionan los libros canónicos del Islam (Corán, Sira, al-Bujári, Muslim), se ciñe a una descripción sensible del paraíso en un sentido literal y material que corresponde a la tradición islámica más ortodoxa. En cambio, en Explanatio Simboli Apostolorum, tratado de teología expositiva, confirma el sentido espiritual, del paraiso que los filósofos musulmanes hicieron (Avicena, Algazel), quienes, como se 
5.1.2.8. Dixit suis quiod in ortu solis vel in occasu non facerent orationem 5.1.2.9. Mandavit suis quod viverent et comederent manu dextra

5.1.2.10. Machometus legit Alcoranum demonibus (20)

5.1.2.11. Asserebat quod dies iudicii debebat esse ante centum annos

5.1.2.12. Loquens de musca... in una ala portat venenum, in altera medicinam

5.1.1.13. Quando gallus cantat, videt angelum; et quando asinus rudit, videt diabolum

5.2. Machometus non fuit mundus sed potius immundus et peccator (21)

5.2.1. Machometus circuibat mulieres suas iacendo cum eis in una hora noctis vel diei et erant undecim

5.2.2. Nos ( = Deus) licentiavimus tibi uxores tuas... et omnes ancillas tuas... et filias patrui tui

5.2.3. Contra istam promissionem et iuramenta coivit cum ea (= Maria Capcia) (22)

5.2.4. Deus constituerat sarracenis satisfactionem iuramentorum

5.2.5. Deus pepercit sibi ( $=$ Machometo) peccata preterita et futura

5.2.6. Rapine licentiate sunt michi

5.3. Machometus nunquam fecit miracula (23)

5.3.1. Expresse innuit quod non erat sibi datum facere miracula

5.3.2. Quod ad nutum eius et preceptum luna fidit se

5.4. Lex quam tradidit fuit immunda, nociva et mala

5.4.1. Sarracenus potest habere quatuor uxores et unam concubinam vel decem vel centum (24)

repetirá más adelante, proporcionan a nuestro autor un argumento complementario sobre la «racionalidad» del sentido espiritual del paraíso que el Cristianismo enseña. Cf. J.M. MARCH: Ramón Martí y la seva «Explanatio Simboli Apostolorum», en «Anuari de l'Institut d'Estudis Catalans», 1980, págs. 493-494.

(20) El autor no hace ninguna diferencia entre demonios, ángeles caídos, cuya actividad consiste en hacer el mal, y los ğinn o genios, espíritus misteriosos, ni ángeles ni demonios, que pueden intervenir en la vida de los hombres para daño o provecho.

(21) Para nuestro autor, como para todos los polemistas antiislámicos, Mahoma dista mucho de ser un ejemplo de vida virtuosa. Dios, por consiguiente, no habria hecho de tal hombre su profeta. El autor utiliza un término duro y despectivo para calificarlo: immundus e immunditia.

(22) Sobre este acontecimiento de la vida de Mahoma, cf. H. HAMIDULLAH: Le prophète de I's/am. I. Sa vie. II. Son oeuvre, L.J. VRIN, Paris, 1959, págs. 210-211.

(23) El autor, más que insistir en el don de profecia, es decir, predecir el porvenir, hace incapié en el poder de hacer milagros como signo de autenticidad de la misión divina del profeta. Las auctoritates aportadas por Ramón Marti en su argumentación se inscriben en un contexto muy determinado. Según el Corán, todo profeta aporta consigo signos que garantizan la autenticidad de su mensaje. A Moisés y a Jesús Dios les ha concedido el poder de hacer milagros, a Mahoma le ha concedido no los milagros sino el hecho de encargarle la transmisión a los hombres de la predicación coránica. Poco después de la muerte de Mahoma comienza un proceso que lfeva a una especie de apoteosis de éste. Para los fieles musulmanes, dado que Mahoma es el «sello de los profetas» (Cor. 33, 40), un fundador de una religión tan grande no podría carecer de tal don. Nació asi una literatura en la que los milagros del profeta serán descritos y comentados. Tal literatura servia para responder a las objeciones de los cristianos y para afirmar la superioridad de Mahoma. El autor del tratado, Ramón Martí, apoyándose en los textos canónicos, a diferencia, por ejemplo de la Apología de al-Kindi, rebate la pretensión de los que atribuyen a Mahoma el don de los milagros. Ramón Marti cita y rebate el milagro más conocido en Europa, el de la luna partida, que se apoya en el versiculo «se acerca la hora y la luna se parte» (Cor. 54, 1). Una elemental exégesis de tal versículo le basta para rechazar el milagro. En esta obra polémica, Ramón Martí no hace la más mínima alusión a otro de los milagros atribuidos a Mahoma y de gran predicamento entre los musulmanes: el de la ascensión nocturna al cielo ( $m i$ rắă, Cor. 17. 1). En la Explanatio Simboli Apostolorum, obra también de Ramón Martí, da la razón de tal omisión: lactavit se ad celos ascendisse, sed nocte et nullo vidente. C.. J.M. MARCH: En Ramón Manti, cit., pág. 481.

(24) El autor escoge del Islam, de acuerdo con el contexto polémico, aquellos aspectos que considera antitéticos con el Cristianismo. De aquellos aspectos de la ley islámica que podrían ser aceptables, aunque discutidos en comparación con los propios, como hicieron los polemistas orientales, nada dice. Como puede observarse, la mayoría de ellos se refieren al matrimonio y a la ética sexual, además del anecdótico sobre el modo de comer, el del derecho al botin y el del juramento incumplido. 
5.4.2. Lex super repudio

5.4.3. Lex cognoscendi mulieres (25)

5.4.4. Lex super conductione mulierum

5.4.5. Lex de effussione seminis extra vas debitum

5.4.6. Lex de modo comedendi... immundum, bestiale et ridiculosum

5.4.7. Lex super rapinis (26)

5.4.8. Lex contra illud «non concupisces"

5.4.9. Lex super peccato sodomitico

6. De fine Machometi (27)

6.1. De infortuniis Machometi: nec prescivit nec potuit se iuvare contra pericula

6.2. De infirmitate ac morte Machometi: mors Machometi fuit vilis, immunda et abhominabilis

7. De veritate et incorruptione Veteris et Novi Testamenti (28)

Si se observa atentamente la estructura del tratado antiislámico, queda claro que se trata de la obra antiislámica, a menudo citada por los autores cristianos medievales en polémica con el Islam, calificada por $N$. Daniel como sformidable work of mediaeval scholarship» (29) y conocida como De origine et progressu et fine Machometi et quadruplici reprobatione eius. Confrontado este título con la estructura del contenido expuesto, se ve que se trata de la misma obra. El autor, después de una introducción donde se exponen los signos del verdadero profeta según $M t$. 7, 15 (verax, vintuosus, miracula, lex bona et sancta), nos da a conocer el origen de Mahoma usque ad predictos quadraginta annos y su falsa inspiración; sigue el desarrollo o progreso de su secta y los signos de que Mahoma carece en su pretensión de profeta, la quadruplex reprobatio (mendax, immundus et peccator, nunquam fecit miracula, lex quam tradidit fuit immunda, nociva et mala); sólo le queda al autor exponer el

(25) Sobre el matrimonio de placer, de carácter temporal, llamado muta, la tradición islámica no está de acuerdo. Ramón Marti toma partido por su existencia no abolida por Mahoma, apoyándose en una auctoritas de Muslim o implícitamente en el Corán ( $v .4,24)$.

(26) El autor no se interesa directamente por la teoria de la guerra santa en el Islam, a diferencia de otros polemistas, en especial los orientales, quizás por las circunstancias históricas. Sólo hay en el tratado dos breves alusiones: ésta de la ley del botín y la de la exposición de las razones de la expansión del Isiam.

(27) RAMÓN MARTi ha empezado su tratado antislámico con de origine et progressu Machometi, ha seguido con de quadruplici reprobatione eius y finaliza con de fine Machometi, con lo que queda patente la confusión en la historiografia. No cabe duda, por otra parte, que su intención es que se pueda comparar entre la vida de Mahoma y la de Jesús, el fundador del Cristianismo. La diferencia cualitativa entre el origen y el fin de uno y otro son evidentes para el autor.

(28) El principio básico de la polémica islámica con el Cristianismo es que éste ha sido corrompido, dado que la Biblia ha sido, a su vez, falsificada. Ahora bien, los autores musulmanes mantenian opiniones diversas sobre el sentido de la palabra coránica tahrif. Unos, TABARI entre ellos, lo entendian en el sentido de falsa interpretación, falsificación del sentido de los textos bíblicos. Otros mantenían que se trataba de un cambio de los textos con fines diversos. Entre éstos cabe destacar a IBN HAZM DE CÓRDOBA (384-456/994-1064); cf. I. DI MATTEO: /l Tahrif od alterazione della Bibbia secondo i musulmani, en «Bessarione", 38 (1922), págs. 64-111. Ya una obra canónica, como la compilación de al-Bujāri, contiene tal acusación: «Dios os ha informado que las gentes del Libro han modificado o alterado en parte los libros de Dios al introducir con las propias manos cosas que no venian de Dios", cf. O. HOUDAS; V. MARÇAIS: Les traditions islamiques, $4 \mathrm{~V}$., París, 1903-1904, t. XCVII, c. XLII, 1. Véase también M. DE EPALZA: La Tuhfa, autobiografía y polémica islámica contra el Cristianismo de 'Abdalläh al-Tary̆umān (fray Anselmo Turméda), Roma, 1971, págs. 404-449.

(29) N. DANIEL: The Arabs and mediaeval Europa, London, 1975, pág. 239. Un aspecto que muestra la calidad de este tratado y el grado de información de su autor es el uso de sus fuentes en un tratado tan corto: Antiguo y Nuevo Testamento, 10 citas; el Corán, 37 citas; al-Bujāin, 24 citas; Muslim, 8 citas; inb Hišam, 5 citas; Ave rroes, 1 cita; al-Kindì, 2 citas; S. Agustín, 1 cita. Las citas muestran, como los especialistas lo han constatado, el conocimiento de esta lengua por parte de su autor 
fin de Mahoma que considera indigno de un profeta (mors Machometi fuit vilis, immunda et abhominabilis). Si Mahoma es un falso profeta, se le plantea al creyente musulmán un último problema antes de aceptar el Cristianismo como verdadera religión: la verdad e incorruptibilidad del Antiguo y Nuevo Testamento, que el autor desarrolla en lo que se podría considerar como la conclusión del tratado.

Hay que concluir, pues, que el tratado antiislámico de contenido idéntico en los manuscritos de El Burgo de Osma, Cambridge y Roma, es el mismo, incluso para quien no lo haya comprobado directamente, que el tratado antiislámico conocido en su título breve como Quadruplex reprobatio o, en su título más amplio, como De origine et progressu et fine Machometi et de quadruplici reprobatione prophetiae eius, según las ediciones de Estrasburgo y de Colonia de mediados del siglo XVI (30). No se trata, pues, de obras diferentes, como escribía L. Robles y repite A. Cortabarría.

Queda otro problema: el de su autoría, puesta en duda una y otra vez por quienes caen en el error anterior. ¿Es su autor Ramón Martí, dominico catalán del siglo XIII? En caso de respuesta afirmativa, ¿escribió Ramón Martí otras obras antiislámicas, como da a entender L. Robles y A. Cortabarria, entre otros? ¿Se trata tal vez de diversos títulos de una misma y única obra, cosa no excepcional en la Edad Media?

A. Dondaine, de quien L. Robles sacó parte de su información, en su artículo ya citado Ricoldiana. Notes sur les oeuvres de Ricoldo da Montecroce, plantea el problema y proporciona una posible solución. En el apartado Oú l'on évoque Raymond Martin A. Dondaine cita al P. Mandonnet, el cual «a attiré l'attention sur un fragment contenu dans le manuscrit Paris, B.N. 4230, ff. 151vb-159rb et portant le titre "Tractatus seu disputatio fratris Ricoldi florentini Ordinis Fratrum Predicatorum contra sarracenos et Alchoranum". Le début de cette pièce la donne comme tiré d'un oeuvre de Raymond l'Espagnol des frères prêcheurs ( = Ramón Martí)... La méthode polémique en question avait pour objet précis de démontrer que Mahomet n'havait pas été un vrai prophète... De fait, nous avons très tôt reconnu la méthode décrite dans un oposcule deux fois imprimé au milieu du XVe siècle à Strasbourg en 1550 et à Cologne en 1551: "De origine et progressu et fine Machometi et quadruplicie reprobatione prophetiae eius". II y avait toutefois une difficulté: notre source attribue la méthode à Fr. Raymond Espagnol O.P. (= Ramón Marti); l'imprimé l'attribue au franciscain Jean Galles. Que le fragment parisien soit substantiellement extrait de l'oposcule "De origine...", la chose est sûre». Seguidamente el P. Dondaine confronta los dos textos y concluye: «La dépendence entre les deux ouvrages est patente: ou bien l'un amplifie l'autre, ou bien celui-ci abrège celui-là». El P. Dondaine se inclina por esta segunda posibilidad y por ello se pregunta: «Quel est l'auteur de celui-ci? Frère Raymond d'Espagne dominicain, c'est-a-dire, Raymond Martin dit le manuscrit 4230; Jean Gales dit l'imprimé». Y añade: «Le "De origine..." suppose que son auteur connaissat l'arabe... tandis que Raymond Martin est justement célèbre pour sa science des langues hébraïque, arabe et chaldèenne. La tradition bibliographique, ininterrumpue depuis le début du XVe siècle, le designait comme l'auteur d'un traité "Contra Sarracenos" qui avait pu être identifié: un tel titre pourrait fort bien s'étendre du "De origine et progressu et fine Machometi et quadruplici reprobatione eius",

(30) Cf. A. DONDAINE: Ricoldiana. Notes sur les oeuvres de Ricoldo da Montecroce, en AFP, XXXVII (1967), pág. 156. 
titre dont l'authénticité n'est pas assurée». El P. Dondaine finaliza mostrando un camino para hallar una respuesta: «L'objet principal du traité était de démontrer que Mahomet ne fut pas un vrai prophète, il devrait être facile d'en retrouver les grandes lignes dans l'oposcule grec "De iudicandis veris et falsis prophetis..." signalé par Quetif-Echard; puisque son auteur était un disciple de Raymond Martin, la concordance aurait valeur démnonstrative». Por último, el $P$. Dondaine nos indica los testimonios manuscritos con el mismo contenido ya citados.

Antes de intentar dar una solución al problema de la autoría de De Seta Machometi o Tractatus contra Machometum o Quadruplex reprobatio o De origine et progressu, etc., atribuida a Ramón Martí, conviene conocer algunos datos sobre este autor y su obra (31).

Ramón Martí nació hacia 1230 en Subirats, localidad cercana a Barcelona. En el convento barcelonés de Santa Catalina tomó el hábito dominico que llevó por espacio de cincuenta años. Parece ser que residió en París un tiempo, donde estudió y conoció personalmente a Alberto Magno. Ramón de Penyafort, maestro general de la orden dominicana entre 1238 y 1240, le orientó hacia los Studia Linguarum (32). En 1250 el capítulo provincial de Toledo le destinó al Studium Arabicum de Túnez para estudiar árabe y cultura islámica. En 1268 Jaime l le nombró miembro de una comisión encargada de examinar los libros de los judíos. Después de un viaje a Túnez, pasó sus últimos años en Barcelona, donde se hizo cargo del Studium Haebraicum. Murió en 1284 ó 1285.

Si los datos sobre su vida son escasos y las fechas no muy seguras, la figura de Ramón Martí, «il primo orientalista europeo» según Ugo Monteret de Villard (33), «le cerveaux des Studia linguarum» según A. Cortabarría (34), se engrandece y enri-

(31) La bibliografía de este siglo sobre Ramón Marti muestra que se trata de un autor poco conocido aún. J. MARCH En Ramón Marti y la seva «Explanatio Symboli Apostolorum», en AlEC, 1908, págs. 443-496, le atribuye Ex planatio y Pugio Fidei. Lo mismo hace M. MENENDEZ Y PELAYO: en Historia de los heterodoxos, Madrid, 1910 y BAC, Madrid, 1965, págs. 521-534. A. BERTHIER: en Un mattre orientalista du Xllle siècle: Raymond Martin OP, en AFP, VI (1936), págs. 267-311, dice: «Parmi les catalogues des ouvrages attribués par Diago a R. Martin se trouve une Somme contre le Coran dont l'existence est actuellement ignorée», págs. 295. M ASÍN PALACIOS: en La escatología musulmana en la divina comedia, Madrid. 1943, le atribuye Explanatio y Pugio Fidei. V. MONTERET DE VILLARD: en Lo studio dell'islam in Europa, Città del Vaticano 1961, pág. 37, añade Capistrum ludaeorum. Lo mismo hace J. MUÑOZ SENDINO: en La Escala de Mahoma, Madrid. 1949 y E. CERULLL: en // libro della Scala, Città del Vaticano 1965, y en Nuove ricerche sul libro della Scala e la conoscenza dell'is/am in occidente, Città del Vaticano 1972. E. BAYERRI BERTOMEU: en Códices Me dievales de la Catedral de Tortosa, Barcelona, 1962, dice: «Se le atribuye una serie de sumas catequisticas contra el Corán escritas lo más probable en árabe, pero aún inéditas», pág. 560. A. CORTABARRIA: en L'étude des langues au Moyen Age chez les Dominicains. Espagne, Orient, Raymond Martin, en MIDEO, X (1970), cita como obras llegadas hasta nosotros Explanatio, Capistrum, Pugio Fidei y, como obras atribuidas a Ramón Martí, Vocabulista in Arabico, De erroribus philosophorum, Quadruplex reprobatio y Suma contra el Corán, a las que añade Summa contra sarracenos y De origine et progressu et fine Machometi en Les sources arabes, cit. pág. 108. E. COLOMER: en el artículo Marti, Ramón de la "Gran Enciclopèdia Catalana», Barcelona, 1982 , vol. 9 , pág. 643 , le atribuye «unes summe perdudes contra l'Alcorà. EVANGELISTA VILANOVA: en Història de la teologia cristiana, cit., le atribuye: Explanatio symboli apostolorum, «unes Summes contra l'Alcorà", Vocabulista in Arabico, Capistrum Judaeorum y Pugio Fidei contra Judaeos.

(32) Los studia linguarum eran escuelas de lenguas de los dominicos donde se estudiaba árabe y hebreo, además de materias religiosas, filosóficas y teológicas en relación con dichas lenguas. Cf. A. CORTABARRIA: L'etude des langues au Moyen Age, cit., págs. 190-223.

(33) Cf. U. MONTERET DE VILLARD: Lo studio dell'islam in Europa nel XIII e nel XIII secolo, Città del Vaticano 1944, pág. 37.

(34) Ci. A. CORTABARRíA: L'étude des lanques au Moyen Age, cit., pág. 225. 
quece al analizar su obra, a pesar de que algunas de ellas no tiene confirmada su autoría. En 1254 escribe Explanatio Simboli Apostolorum, obra teológico-apologética en que comenta el credo de los Apóstoles, destinada al uso de los predicadores; en 1267 escribe Capistrum ludeorum de carácter polémico contra los judios, para uso de los religiosos de su orden en sus relaciones con aquéllos; pero su obra más conocida es el famoso Pugio contra ludeos, según los manuscritos antiguos, o Pugio Fidei adversus mauros et iudaeos, según las ediciones impresas, compuesta en 1278. Se le atribuyen: Vocabulista in arabico, diccionario latino-árabe y árabe-latino, de fecha dudosa; Tractatus de erroribus philosophorum, Aristotelis, Avicennae, Algazelis, Alkindi et Rabbi Moysys o, de forma abreviada, De erroribus philosophorum. Por último, se le atribuye también la autoria de una obra polémica contra el Islam, conocida bajo diversos títulos y de contenido idéntico, lo que ha inducido a algunos, como ya se ha dicho, a afirmar que Ramón Martí habia escrito varias obras antiislámicas: Summa contra el Corán, según F. Diago (35); Contra Sarracenos, según Luis de Valladolid (36); De origine et progressu et fine Machometi et quadruplici reprobatione prophetiae eius, según su edición de Estrasburgo en 1550 y de Colonia en 1551; Tractatus contra Machometum, según el ms. 28b., s. XIV de los Archivos Generalicios O.P. en Roma y el ms. Dd. I, s. XIV de la Universidad de Cambridge; De Seta Machometi, según el ms. 46 de la Biblioteca Capitular de la Catedral de El Burgo de Osma.

Llegados a este punto podemos establecer una serie de puntos de reflexión:

1. Ramón Martí, autor de Pugio Fidei y de Explanatio Simboli Apostolorum, es también el autor de una obra Contra Sarracenos.

2. La tradición bibliográfica ininterrumpida desde principios del siglo XV lo señala como el autor de un tratado polémico antiislámico.

3. Las datos biblio-biográficos de Ramón Martí confirman la posibilidad de este hecho.

4. El ms. París, B.N., Lat. 4230, ff. 151vb-159vb, parece indicar que el autor de un fragmento Contra Sarracenos copia al autor del Pugio Fidei.

5. El parecido entre diversos fragmentos de Explanatio Simboli Apostolorum de Ramón Martí y el contenido de los manuscritos citados es real. La comparación entre las dos obras pueden indicarnos si el autor de ambas es él mismo.

De lo dicho cabe hacer dos afirmaciones:

1. Existe una obra polémica contra el Islam que recibe diferentes títulos:

- Summa contra el Corán, según F. Diago.

- Contra Sarracenos, según L. de Valladolid.

- De origine et progressu et dine Machometi et quadruplici reprobatione prophetiae eius, según las ediciones de Estrasburgo y Colonia de mediados del s. XVI.

- Tractatus contra Machometum, según el ms. 28b. de los Archivos Genera-

(35) Cr. F. DIAGO: Historia de la Provincia de Aragón de la Orden de los Predicadores desde su origen hasta el año 1600, Barcelona 1599, pág. 137.

(36) Cf. H.CH. SCHEEBEN: Die Tabulae Ludwigs von Valladolid in Chor der Predigerburger con St. Jakob in Paris, en AFP, 1 (1930), pág. 223-236. 
licios O.P. en Roma y el ms. Dd. I de la Universidad de Cambridge.

- De Seta Machometi, según el ms. 46 de la Biblioteca Capitular de la Catedral de El Burgo de Osma.

2. El método para saber si esta obra de polémica antiislámica, que recibe diversos títulos, es debida a Ramón Martí, puede determinarse comparando la obra Explanatio Simboli Apostolorum, debida sin lugar a dudas a Ramón Martí, con esta obra polémica contra el Islam. Podría también tenerse en cuenta otras obras de Ramón Martí, pero dado el carácter de De Seta Machometi - Quadruplex reprobatio, etc., y el de Explanatio Simbolo Apostolorum, basta para tal fin, el de su autoría, como se verá enseguida, limitarse a esta última.

Si se comparan las obras Explanatio Simboli Apostolorum y el tratado antiislámi$\mathrm{co}$, no sólo se verá que una parte de ambas es idéntica, sino que se trata de dos obras complementarias, compuestas en una misma época. La obra Explanatio Simboli Apostolorum es un breve tratado de teología expositiva, pero también un tratado de teología polémica. Ramón Martí escribe para uso de los predicadores que ejercían su misión entre los judíos y los musulmanes. Mas, bajo el aspecto polémico, está sobre todo interesado su autor por la posición islámica (37). A esto se debe que, antes de exponer y demostrar el dogma cristiano, dedique una parte de la obras a probar que las Escrituras están «incorruptas», aspecto contestado por el Islam. ¿Ha sido intención del autor que ambas obras formaran parte de un todo? Una vez demostrado que Mahoma no fue profeta de Dios, objetivo del tratado De Seta Machometi o Quadruplex reprobatio, y probada la integridad y veracidad del Antiguo y Nuevo Testamento, pueden ser expuestas y, por consiguiente, admitidas las verdades fundamentales del dogma cristiano. Se comprende así que su exposición sobre la veracidad e integridad de las Escrituras sea casi la misma en Explanatio Simboli Apostolorum, donde inicia el tratado, y en De Seta Machometi o Quadruplex reprobatio, donde lo concluye.

En las obras polémicas de autores musulmanes contra el Cristianismo puede observarse que los puntos divergentes entre el Islam y el Cristianismo eran cuatro: a) el Cristianismo ha sido corrompido, como principio básico; b) los escritos revelados demuestran que la Biblia ha sido falsificada, que Mahoma ha sido anunciado por los profetas bíblicos, que el Corán es la prueba del carácter profético de Mahoma; c) el dogma: Dios, Trinidad, Cristología, Redención, etc.; d) la práctica religiosa: culto, rito, derecho, moral (38). Pues bien, el tratado Explanatio Simboli Apostolorum y el tratado antiislámico forman una unidad donde todos estos puntos son refutados. En el tratado antiislámico, bajo sus diversos títulos, se contesta que Mahoma sea un verdadero profeta así como la falsificación de la Biblia. En Explanatio Simboli Apos-

(37) A este respecto hay que notar que el autor sólo polemiza con el Islam, como demuestran las expresiones siguientes: error Machometi et illorum sarracenorum; in likris arabicis; in Alcorano; hoc idem testatur Alcoranus; unde quidam iudeus sic exponebat sarraceno; Machometus ussus est dicere et scribere; quod etiam a sarracenis habetur; et sic nichil proderit intercessio Machometi qui dixit quod; unde dicitur in libro dicto Albuchan et in libro dicto Muzlim; sicut dicit Machometus; secundum sectam sarracenorum; et ita anichilatur fabula paradisi Machometi; in errorem induxit sapientes sarracenorum; in quibus dixit Machometus; sarraceni aliqui nituntur probare.

(38) Cf. E. FFITCH: /slam und Christentum in Mittelalter Beiträge zur Geschichte der muslimchen polemik gegen des Christentum in arabische Sprache. Breslau, 1930, págs. 39-150; G.C. ANAWATI, Polémique, cit., págs. 379-380 
tolorum, después de probada la veracidad e integridad de la Biblia, se explican los aspectos dogmáticos del Cristianismo, las cuestiones referentes a la práctica religiosa, sin olvidar el Islam como adversario directo a refutar.

Por otra parte, en dos puntos concretos, el del matrimonio-ética sexual y el del paraíso, el tratado Explanatio Simboli Apostolorum desarrolla ampliamente, con toda suerte de auctoritates y pruebas, lo que de forma sintética se dice en el tratado antiislámico. Aquí el autor se propone desacreditar el Islam. Es por ello que se limita a exponer lo que el Corán y los repertorios de hadices debidos a al-Bujärì y Muslim, aceptados como norma canónica y considerados como libros sagrados después del Corán (39), dicen de Mahoma y de su doctrina, y a exponer los principios cristianos, pero de forma breve y que se pueden hallar desarrollados en Explanatio. En vistas a su objetivo, como cristiano, ello basta. La finalidad de Explanatio Simboli Apostolorum, por su parte, manual dogmático y apologético para uso de los que debían ejercer su apostolado en los medios donde se hallaban los Studia linguarum, es exponer lo que el cristiano debe creer y practicar. Basta aquí una breve indicación sobre lo que el Islam enseña y que el cristiano debe rechazar. De ahí la complementariedad de los dos tratados sobre el punto común del matrimonio.

Otro de los puntos comunes en las dos obras es el de la beatitud del Paraíso. Se podría aquí alegar una cierta divergencia, dado que en el tratado antiislámico el autor expone la idea sobre el Paraíso comprendido en un sentido material, según una interpretación literal del Corán. Por el contrario, en Explanatio Simboli Apostolorum, haciendo uso de fuentes árabes, expone las ideas de los filósofos musulmanes sobre la beatitud del Paraiso en un sentido espiritual. Pero no hay en ello contradicción. En De Seta Machometi o Quadruplex reprobatio, obra sobre todo polémica, el sentido material del Paraíso opuesto al sentido espiritual propio del Cristianismo basta. En Explanatio Simboli Apostolorum, tratado de teología expositiva, a la vez que repite las auctoritates de De Seta Machometi, confirma el sentido espiritual de Paraíso en el Cristianismo con la misma interpretación, también espiritual, del Paraíso que los filósofos musulmanes hicieron, quienes, interpretando en sentido espiritual la exposición totalmente material del Corán, proporcionan a Ramón Martí un argumento complementario sobre la «racionalidad» del sentido espiritual del Paraíso que el Cristianismo enseña.

Concluyendo: Una misma obra recibe diversos títulos; constatamos partes idénticas en el De Seta Machometi o Quadruplex reprobatio y en Explanatio Simboli Apos tolorum; podemos ver que el tratado antiislámico y Explanatio Simboli Apostolorum son complementarios. Cabe, pues, hacer tres afirmaciones:

1. Los tratados De Seta Machometi o Tractatus contra Machometum o De origine et progressu et fine Machometi et quadruplici reprobatione prophetiae eius - Quadruplex reprobatio y Explanatio Simboli Apostolorum son obra de un mismo autor: Ramón Martí, dominico catalán del siglo XIII.

2. Nada indica que Ramón Martí escribiera diferentes obras polémicas contra el Islam. Los diversos títulos corresponden a un mismo contenido.

(39) Cf. F.M. PAREJA: La religiosidad musulmana, BAC, Madrid, 1975, pág. 40; H.A.R. GIBB; J.H. KRAMERS Shorter Encyclopaedia of Islam, Leiden-London, 1961, art. al-Bujari, pág. 65 y art. Muslim pág. 417. 
3. Explanatio Simboli Apostolorum y De Seta Machometi o Tractatus contra Machometum o De origine et progressu et fine Machometi et quadruplici reprobatione prophetiae eius o Quadruplex reprobatio formarian parte de un todo, de un mismo proyecto, pero con una entidad suficiente para poder ser leidas de manera independiente una y otra obra. Y así han llegado hasta nosotros. 